\title{
Comunicação vem do nascimento
}

Juliana Winkel

Jornalista, especialista em Gestão da Comunicação, mestranda em Ciências da Comunicação e editora executiva da revista Comunicação \& Educação.

E-mail: juli.santos@usp.br

Resumo: A jornalista e educadora Marina Rosenfeld, que iniciou sua atuação em Educomunicação como jovem participante das ações da Cidade Escola Aprendiz, e atualmente coordena o Núcleo de Comunicação da mesma organização, fala sobre sua trajetória pessoal na área e sobre o conceito de Comunicação Comunitária, que compreende o trabalho comunicativo junto às comunidades.

Palavras-chave: Educomunicação, escola, aprendizado, comunicação comunitária, jornalismo.
Abstract: The journalist and educator Marina Rosenfeld, who initiated her performance in Educommucation as a young participant of the NGO Cidade Escola Aprendiz actions and is now coordinator of its Núcleo de Comunicação, talks on her professional trajectory and on the concept of Community Communication, that comprises the communication work in communities.

Keywords: Educommunication, school, learning, community communication, journalism.

Em meados da década de 1990, a então adolescente Marina Rosenfeld se interessou em colaborar com um projeto envolvendo comunicação e educação realizado em sua escola. O veredicto da coordenação da instituição, porém, foi de que ela, às vésperas do vestibular, não poderia participar devido à necessidade de empregar seu tempo estudando o conteúdo do currículo formal. Foi preciso um trabalho de convencimento junto aos educadores para demonstrar que o projeto seria, também, uma maneira eficaz de estudar. Hoje trabalhando como Gerente do Núcleo de Comunicação Comunitária da Associação Cidade Escola Aprendiz - mesma iniciativa da qual participou como adolescente, e que então dava seus primeiros passos -, ela fala sobre suas experiências como jornalista, educadora e sobre as mudanças do conceito de comunicação e educação ao longo do tempo, tanto na escola como na comunidade.

\section{OUTRAS MANEIRAS DE ESTUDAR}

Eu tenho uma história totalmente conectada à Educomunicação. No ano de 1997, estudava num colégio onde o jornalista Gilberto Dimenstein, após concluir o mestrado em Educação nos Estados Unidos, realizava um projeto de cidadania dentro da escola. Nessa época, a internet ainda estava surgindo e as pessoas conheciam muito pouco sobre ela. Dentro do projeto, Gilberto queria 
comunicação \& educação • Ano XVII • número 1 • jan/jun 2012

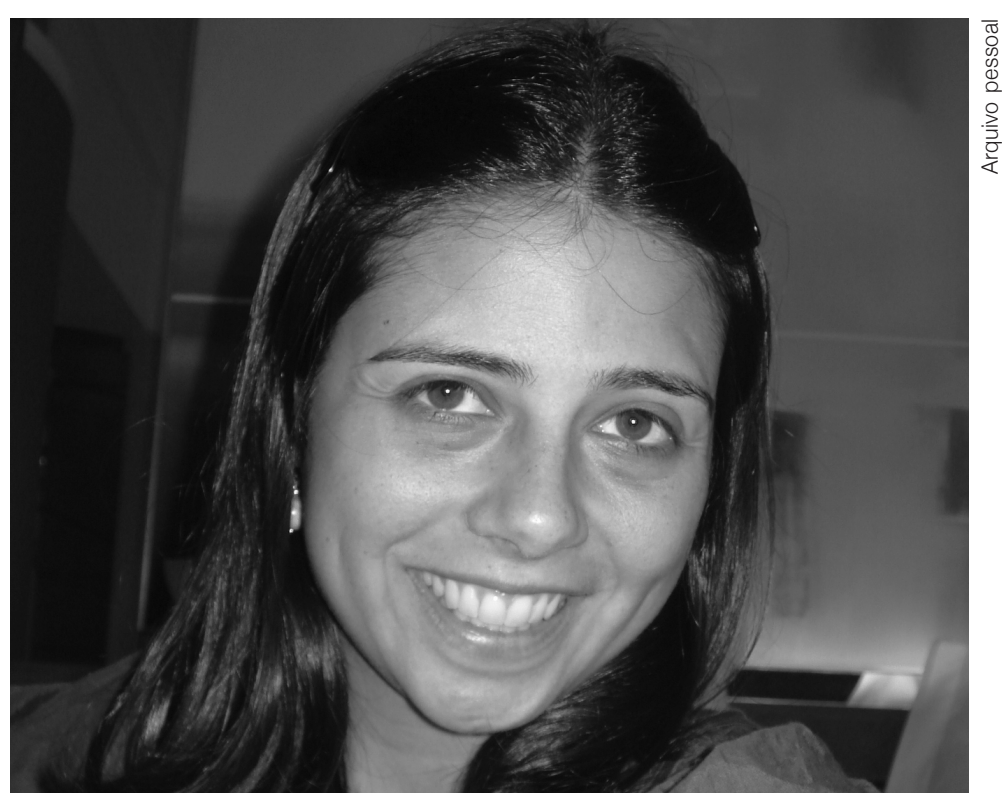

Marina Rosenfeld.

que os jovens participassem da criação do Portal Aprendiz - hoje um dos principais sites de educação de conteúdo aberto do país. Seria um site dedicado a discutir novas formas de se fazer educação, não só formal, mas também não formal e informal, destacando experiências e inovações nessa área.

Eu estava cursando o segundo colegial, tinha então 16 ou 17 anos. Naquela época, já me chamava bastante a atenção a questão da educação, porque dentro da escola existia uma divisão entre quem era melhor ou pior aluno - e eu já me questionava muito em relação a como trabalhar o potencial dos alunos. Foi quando Gilberto ofereceu, àqueles que tivessem interesse no assunto, a possibilidade de participar do projeto, escrevendo para o novo site. Estávamos na época de pré-vestibular e a proposta veio ao encontro das minhas expectativas, pois eu já pensava em trabalhar com comunicação e jornalismo. Porém, quando decidi me voluntariar para o site, a direção da escola disse: "Você não pode ser escolhida porque precisa estudar. Não tem que estar ali, mas sim em casa, todos os dias, estudando".

Essa resposta me chocou, pois eu pensava que aquela atividade seria justamente uma forma diferente de estudar. Decidi "bater de frente" com a coordenação. Um dia encontrei o Gilberto no corredor da escola e disse que gostaria muito de participar do projeto, mas que não haviam permitido, sob a alegação de que eu precisava estudar. Ele me respondeu: "Eu também fui considerado 'mau aluno' até entender que existem outras formas de estudar. Toda a minha história com a educação começou porque eu questionava a forma como as coisas nos eram apresentadas. Então, justamente porque você é 'má' aluna, vai participar do projeto".

Finalmente, comecei a participar da construção do site. E me surpreendi quando cheguei ali, pois percebi que o objetivo do trabalho não era simplesmente elaborar textos ou notas, mas sim aprender a trabalhar com comunicação 
através dos diversos instrumentos possíveis - a foto, a internet, o texto, o rádio. Havia jornalistas recém-formados que acompanhavam os jovens em atividades de pesquisa, português e programação. Com o passar do tempo, agregamos jovens de outras escolas particulares e também de escolas públicas. E ali fui desenvolvendo a capacidade de me expressar, a autonomia e a corresponsabilidade a partir do que, na época, já chamávamos de Educomunicação.

Foi interessante o que aconteceu ao longo do tempo. Nesse projeto, enquanto aprendíamos a construir sites, outras atividades se desenvolviam. Discutíamos história da arte, caminhávamos pelo bairro fotografando as ruas, descobrindo coisas. Lembro-me, por exemplo, de que soubemos o que era o Estatuto da Criança e do Adolescente quando fizemos um site sobre ele. E foi a partir deste projeto de Educomunicação que surgiu a Cidade Escola Aprendiz, em 1997 - quando fizemos a primeira proposta oficial de organização em que jovens desenvolviam sites para instituições não governamentais. Nessa época eu já trabalhava como estagiária no projeto, e a Educomunicação fez com que o transformássemos em instituição. Muitas ações e projetos depois, hoje trabalhamos com o que chamamos de Comunicação Comunitária: procuramos identificar o que existe de interessante em determinado território e como trabalhar a comunicação para o desenvolvimento local, de forma que as pessoas comecem a trocar notícias e informações de seu interesse.

Paralelamente a isso, nos envolvemos com outras áreas, como a cultura, e hoje trabalhamos totalmente voltados à educação integral. Mas a comunicação em si faz parte de todo esse processo, de toda a trajetória da instituição - e também da minha trajetória. Minha formação, enquanto profissional e enquanto

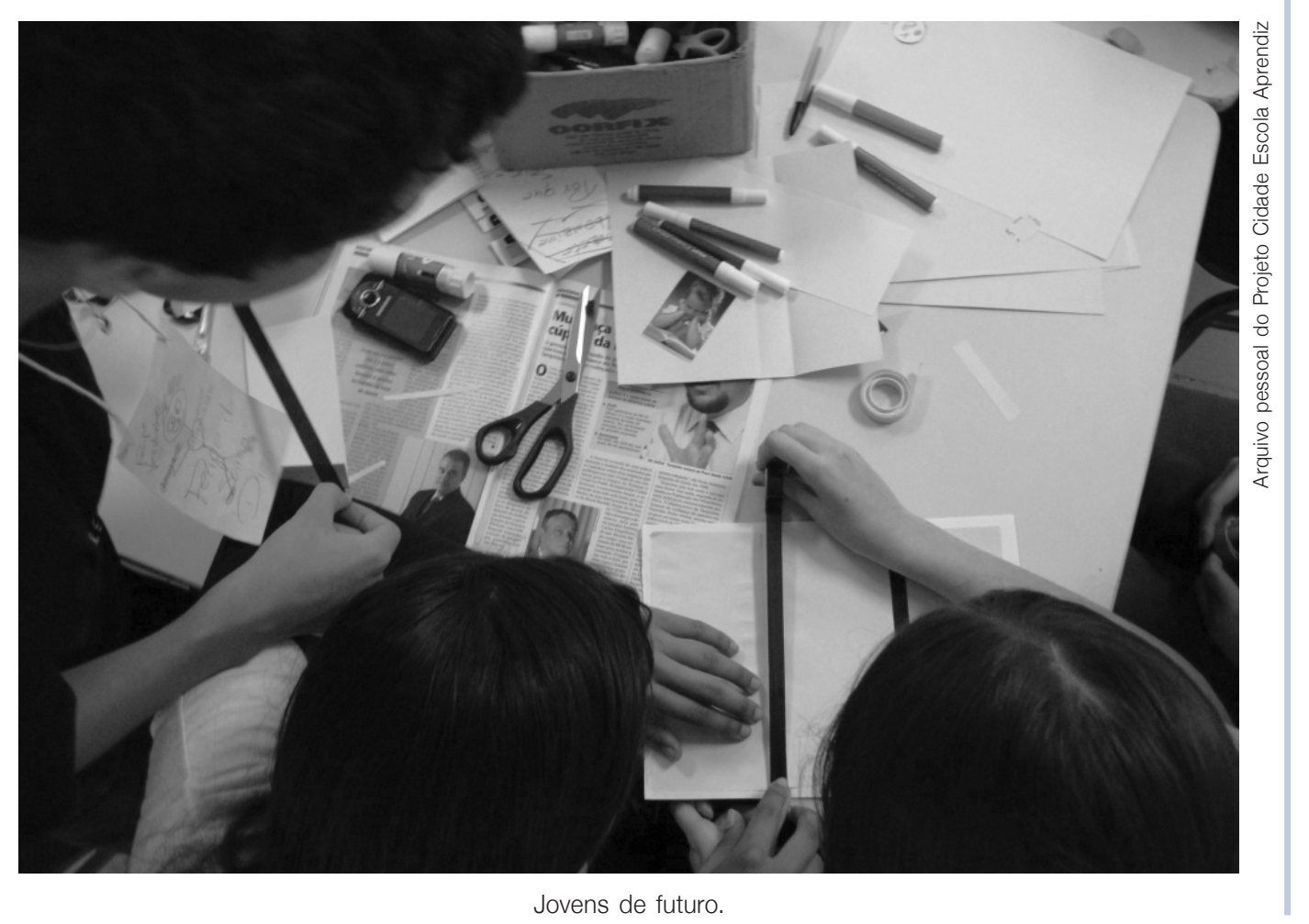


comunicação \& educação • Ano XVII • número 1 • jan/jun 2012

pessoa, ganhou muito com a Educomunicação. Quando tudo isso começou, eu ainda era uma garota que imaginava fazer jornalismo. E depois que me envolvi no projeto, pensei: "Que bacana estar no meio disso, não só para mim, mas desenvolvendo essas atividades com outras pessoas".

Transformei-me em educadora, depois trabalhei como jornalista durante vários anos em outros lugares - mas sempre próxima a projetos de Educomunicação. Nunca me desvinculei desse projeto, pelo qual tenho paixão. Acredito que a Educomunicação, em si, é uma forma de explorar os potenciais das pessoas.

Finalmente, passei a trabalhar como Coordenadora de Projetos e hoje sou Gerente do Núcleo de Comunicação Comunitária da Cidade Escola Aprendiz, com ações em vários cantos do país. Passamos a trabalhar na perspectiva de articulação de redes, direcionando potenciais em função do desenvolvimento das comunidades. Realizamos projetos de Comunicação Comunitária em algumas regiões dentro de São Paulo, no Vale do Paraíba e em diversos outros lugares, sob a perspectiva de políticas públicas. Desenvolvemos uma série de experiências que nos ajudam a trabalhar com as Secretarias de Educação, criando instâncias dentro da escola para que os jovens tenham espaços de diálogo e para que a escola possa se abrir a eles e discutir suas questões. Organizamos também agências de comunicação comunitária, em que a própria comunidade produz e veicula notícias. Hoje contamos com quatro agências nas quais as pessoas elaboram pautas sobre suas regiões, mobilizam seus vizinhos e divulgam as notícias.

Nosso trabalho é fazer a facilitação desse processo. Acreditamos que a Comunicação Comunitária é a possibilidade que as pessoas têm de horizontalizar a comunicação, deixando de ser apenas receptoras, mas passando a atuar também como emissoras da informação. Temos entendido a Comunicação Comunitária como um instrumento para fortalecer as comunidades, usando a comunicação como uma ferramenta de mobilização. Não é preciso ser jornalista para se comunicar. A partir do momento que nascemos, já estamos nos comunicando. Por meio da Comunicação Comunitária, mostramos que as pessoas podem e devem usar esse potencial para comunicar o que é de interesse para si e para a comunidade, sem esperar que outros venham lhes dizer o que comunicar.

Essa evolução se reflete na história e no perfil do público do próprio projeto. Se no início, quando o Aprendiz era apenas um site, os jornalistas e educadores atuavam como transmissores de conhecimento, atualmente, e cada vez mais, temos nos percebido como facilitadores dos processos. No início, existia a preocupação de trabalhar o domínio das técnicas e ferramentas das diferentes mídias com os jovens. Era uma novidade trabalhar com rádio na internet, por exemplo. Hoje eles conhecem esses instrumentos melhor do que nós e chegam a nos ensinar a operá-los. Os jovens, hoje, vêm com expectativas muito mais elevadas do que as que nós tínhamos na idade deles. As possibilidades são inúmeras e todos têm acesso a tudo o tempo todo. Nosso papel como educadores, portanto, se concentra em facilitar, mediar e mostrar como podem utilizar o potencial dessas ferramentas. Se sabem produzir um vídeo, operar uma rádio, como é que podem usar isso? Como podem levar isso para a escola, por exemplo, e falar sobre as questões importantes para eles? 


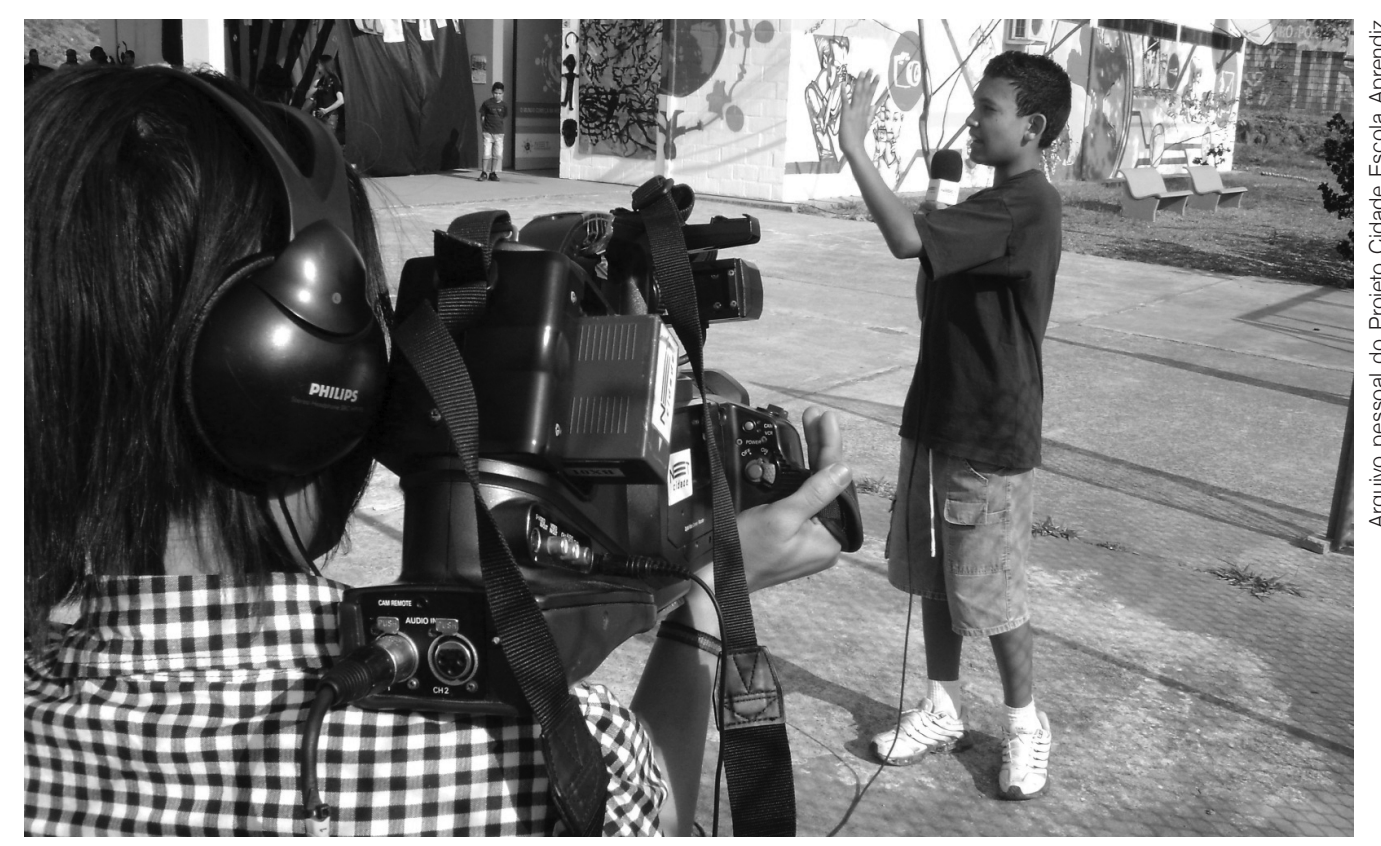

Jovens repórteres.

Claro que muito dessa mudança se deve à popularização da internet, essa "superferramenta" onde se pode encontrar de tudo e, ao mesmo tempo, fazer comunicação com uma capacidade de capilarização impressionante, não à toa chamada viral. Por meio dela, existem possibilidades muito grandes de se chegar a qualquer lugar. No entanto é preciso atenção, pois existem muitos lugares, ainda, que não têm acesso a ela e que não possuem ainda a cultura on-line. Dessa forma, não adianta abrir mão de todos os outros recursos de comunicação em favor da internet. É preciso observar as características do local e, então, entender qual o potencial mobilizador de cada ferramenta. Obviamente, o acesso à internet nas regiões centrais é mais fácil, enquanto nas regiões periféricas ainda se usa muito o rádio, por exemplo. Outro ponto fundamental a se levar em consideração é o fato de que a informação não é, necessariamente, conhecimento. As possibilidades de comunicação hoje são muito maiores, mas ao mesmo tempo é mais difícil filtrar o que é importante. Entre os desafios da comunicação de hoje, está o de administrar o excesso de informações.

\section{EDUCOMUNICAÇÃO: FORMAL OU INFORMAL?}

Não acredito que existam modelos ou métodos fechados para o trabalho com Educomunicação. O que existem são percepções, reflexões. Nós trabalhamos de acordo com as possibilidades e particularidades de cada território - e também com base no que aprendemos com experiências anteriores. Por exemplo, temos um trabalho desenvolvido em parceria com a Secretaria Municipal de Educação de Belo Horizonte chamado Escola Integrada, que é um programa de educação integral por meio do qual conseguimos construir, ao lado deles, reflexões e experiências sobre como trabalhar com Educomunicação dentro da escola. 
comunicação \& educação • Ano XVII • número 1 • jan/jun 2012

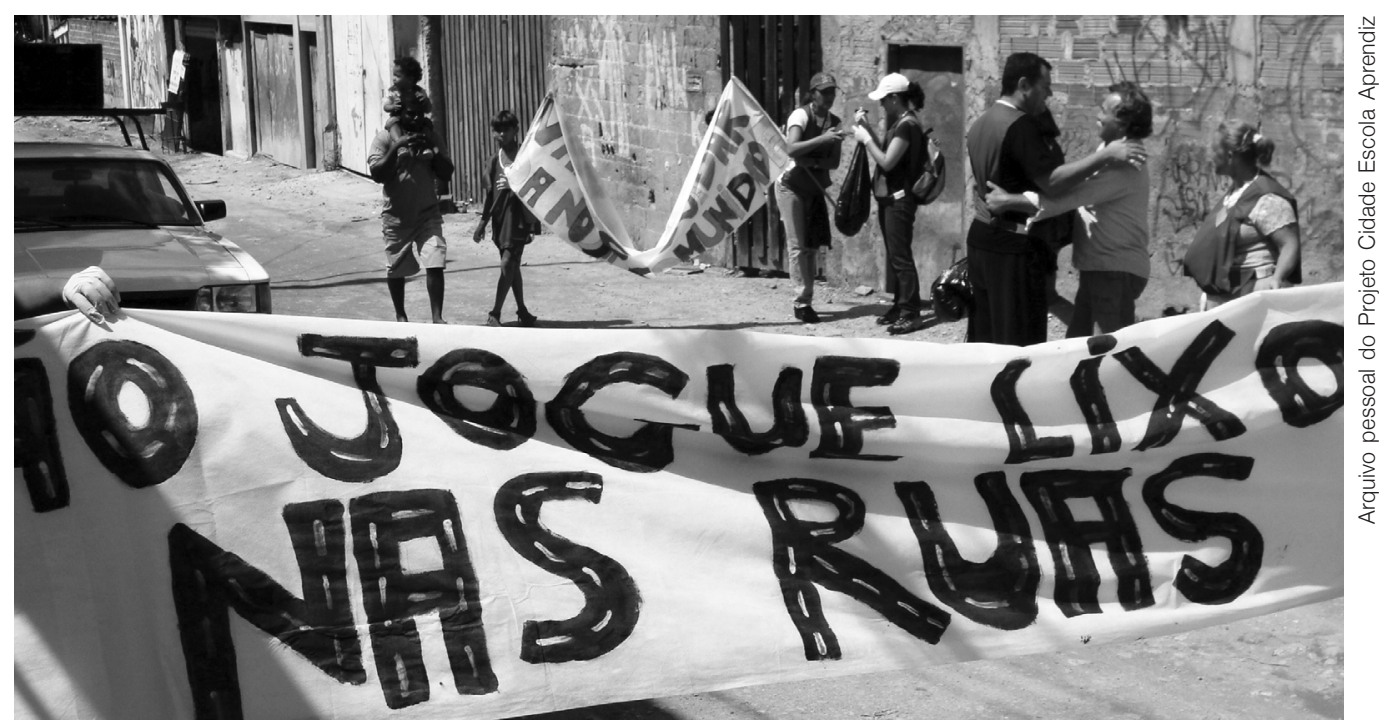

Mobilização na represa Guarapiranga-SP

Procuramos focar nossa atuação nos parceiros locais. A partir daí, identificamos quem são os agentes com potencial comunicativo - que pode ser até mesmo o vendedor de balas na frente de uma escola, conhecedor do movimento e das pessoas do lugar. Dependendo da ação comunicativa e de nosso público, é mais eficaz contar com a participação dele do que utilizar um jornal, por exemplo. Da mesma forma, é possível trabalhar com a comunidade, com a Secretaria, com os educadores e com diversas pessoas.

Estamos em um momento de aprofundamento. Nos últimos anos, viemos descobrindo uma série de possibilidades da comunicação. Temos percebido caminhos para aproximar a comunidade não só da produção de conteúdo, mas também do entendimento de sua capacidade de comunicação e mobilização. Nosso objetivo seguinte é, depois de conquistada a autonomia da comunidade nesse processo, nos retirar aos poucos. Isso se reverte em muitos benefícios para a comunidade, pois, a partir do momento que as pessoas começam a se comunicar, passam a se conhecer melhor também e a se articular em redes.

Acredito que a educação formal está abraçando cada vez mais o uso da comunicação. Começa-se a perceber a capacidade de mobilização e as possibilidades de aprendizagem oferecidas por ela. Temos vários exemplos de como a escola tem utilizado a comunicação de forma conectada às disciplinas, ao mesmo tempo que se constitui também num tema para trabalho. Claro que existe o risco de, ao se dizer que se está fazendo Educomunicação, as escolas simplesmente passarem a ensinar técnicas de comunicação - e aí cabe também uma discussão em relação ao termo. Sempre digo que, se tivermos que fazer oficinas de comunicação para ensinar técnicas, será nossa falência. Precisamos usar a comunicação para mobilizar e articular todos os atores da comunidade, ao lado dos veículos e organizações - até mesmo o pipoqueiro da escola, que adoraria trabalhar com comunicação, mas muitas vezes não sabe por onde começar. A ideia é trazer todas essas pessoas para que troquem experiências entre si. 